\title{
FORMAÇÃO POLÍTICO-JURÍDICA DO TERRITÓRIO BRASILEIRO
}

\author{
José Roberto Franco da Fonseca \\ Professor Associado aposentado da Faculdade de \\ Direito da Universidade de São Paulo
}

Resumo:

A formação das fronteiras atuais do Brasil mostra como o território do Estado é o resultado de um processo histórico composto por diferentes fases de tempo. O território do Estado, assim, além das dimensões do comprimento, largura e profundidade, apresenta mais essa quarta dimensão, histórica e cronológica. Isso se torna claro quando se contempla o processo de formação das fronteiras do Brasil, no período dos descobrimentos, no da expansão interna e no posterior período da fixação dos limites jurídicos, por meio de tratados e arbitragens.

\begin{abstract}
:
The formation of the current boundaries of Brazil shows that the territory of any State is the result of a historical process developed in different stages. The territory of any State, thus, is composes of three dimensions longitudinal, wideness, height , and a fourth one, its historical nature. This makes clear when we consider the process of formation of the territory of Brazil through its history, beginning with the discovery, the expansion of its population and later treaties and agreements.
\end{abstract}

Unitermos: território estatal; limites do Brasil.

1. Introdução

1.1 - O território como elemento constitutivo do Estado

O documento histórico que certifica o nascimento do Estado moderno consubstancia-se nos dois Tratados de Westphalia (1648), que puseram termo à Guerra dos Trinta Anos. Neles se redesenha a nova ordem mundial: a Europa seria constituída de Estados (reinos, principados) soberanos (iguais e independentes).

A caracteristica de independência, ínsita à soberania, punha-se em dois sentidos: a. no horizontal (igualdade, em relação aos demais Estados); b. no vertical: 
independência em relação ao extinto Sacro Império Romano Germânico (já, então, mera figura nominal), na direção superior e, na inferior (e interior às fronteiras das entidades estatais nascentes), supremacia absoluta, com a extinção dos poderes locais e atomizados que caracterizavam a estrutura política-feudal.

Embora tal certificação documental tenha ocorrido em Westphalia, em 1648, na verdade a passagem do feudalismo para a modernidade ocorreu através de longo processo histórico, em que o monarca foi, aos poucos, cada vez mais centralizando os poderes de editar leis, julgar e administrar (manter exércitos, cobrar tributos), poderes que estavam nas mãos dos senhores locais (duques, barões, marqueses, condes).

Com efeito, o absolutismo monárquico e sua fundamentação na teoria do Direito Divino já encontravam sustentação na doutrina (Jean Bodin) no século XVI; e modernos historiógrafos (como Burns) datam o marco inaugural de tal absolutismo, em 1485, com a ascensão ao trono da Inglaterra de Henrique VII, o primeiro Tudor, após a Guerra das Duas Rosas; seguindo-se-lhe os mais célebres membros da dinastia: Henrique VIII (1509-1547), Isabel (1558-1603), até que, morrendo Isabel sem deixar descendentes, assume o trono seu primo Jaime I (escocês, Stuart) e instaura a monarquia de Direito Divino. Os mesmos historiógrafos situam o início do processo, em França, com Luís IX e Felipe IV (séculos XIII e XIV); e, na Rússia, com Ivan, o Grande (1462-1505), e Ivan, o Terrivel (1533-1584), este último tendo derrotado definitivamente os "boiardos" (senhores feudais rurais). Na própria Ibéria, já havia monarquias absolutistas bem estruturadas, na época contemporânea aos descobrimentos (v. infra n. 3).

São geralmente identificáveis as cassas, algumas remotas e outras mais próximas, da formação do Estado como modernamente concebido: a revolução comercial, a fundação dos impérios coloniais, a política mercantilista advinda da introdução de metais preciosos na Europa, a reforma protestante.

Pois bem, os autores obtêm geralmente consenso em apontar três elementos presentes ao Estado, desde seu surgimento, como constitutivos de sua própria essência: território físico, povo e governo. Há dissensão quanto à soberania. Para Bodin, ela é atributo do rei, na monarquia; atributo do povo, na república. Entende-se, modernamente, a soberania como atributo do Estado (coincidente com a personalidade jurídica de Direito Internacional), que permite a este atuar na sociedade internacional com as características de igualdade e independência. 
1.2 As porções (terrestre, marítima, fluvial e lacustre, aérea) do território estatal

O território é a base física, geográfica e geológica, em que se assenta o Estado. É delimitado por fronteiras (cujos velhos e novos significados serão ventilados adiante, n. 1.3).

O território é fenômeno complexo, suscetível, pois, de escandir-se anatomicamente. Com efeito, o território estatal compõe-se de porções de natureza diversa: elementos físicos sólidos, líquidos e gasosos. Há quatro porções que, em síntese integrativa, fazem surgir o território estatal: a. território terrestre; b. território marítimo; c. território fluvial e lacustre; d. território aéreo.

\section{a. Território terrestre}

O território terrestre, por seu turno, é também síntese integrativa de três porções heterogêneas: solo (ou superfície), subsolo, plataforma continental. 0 subsolo vai até o centro da Terra: a figura é uma pirâmide irregular côncava, de base semi-esférica (o solo ou superfície), invertida, tendo o vértice no centro da Terra, a uma distância de aproximadamente 6.600 quilômetros da base. Quanto à plataforma continental, sua noção jurídica difere do conceito geológico: para o jurista, a plataforma só tem seu início no limite externo do mar territorial.

O título de aquisição original do território brasileiro por Portugal foi a descoberta. Tal era, na época, o fundamento jurídico para a reivindicação de soberania da terra nullius. Sendo o Direito Internacional construído paulatinamente na Europa, a partir dos descobrimentos, outro título foi ali adquirindo foros de juridicidade: a conquista; mas, dada a visão eurocêntrica de então, a conquista somente era tida como título aquisitivo de território quando houvesse resistência armada oposta pelos ocupantes da terra (fato que ocorreu com relação às mais importantes descobertas espanholas na América, diferentemente do que ali ocorreu com as descobertas portuguesas).

\section{b. Território marítimo}

Compreende tal porção, por seu turno, o mar territorial (extensão, até 12 milhas, a partir da preamar ou da linha-base) e as águas interiores (aquelas 
porções de mar contidas dentro e aquém da linha-base), observando-se que, por ficção, a linha-base desvia-se de sua direção reta sempre que encontre instalação portuária, para envolver a referida instalação. A distinção é importante, porque o mar territorial está sujeito ao princípio da livre passagem inocente, regime jurídico que se não-aplica às águas interiores.

c. Território fluvial e lacustre

Os rios ou são inteiramente nacionais (como o São Francisco) ou são internacionais; estes, por seu turno, podem ser sucessivos (como o Amazonas) e/ou contíguos (como o Paraná, entre Brasil e Paraguai; e Uruguai, entre Brasil e Argentina). No caso dos contíguos não-navegáveis, o critério da divisão longitudinal é o da eqüidistância; no caso dos navegáveis, o critério é o da fixação do limite divisório pelo talvegue. O Amazonas encontra-se aberto à navegação comercial, em bases não-discriminatórias, por ato unilateral, de 1866, e é objeto do Tratado de Cooperação Amazônica, celebrado em Brasília, em 3 de julho de 1978. A Bacia do Prata foi objeto do Tratado celebrado anteriormente em Brasília, em 23 de abril de 1969.

Os lagos internacionais subsumem-se em regimes jurídicos específicos, normalmente fruto de convenção.

\section{d. Território aéreo}

O Estado exerce soberania plena sobre a porção atmosférica de seu território (tal porção tem por limite superior o término da atmosfera); ali não-vige o direito de passagem inocente.

Três convenções de Chicago, de 1944, regem o regime jurídico da aviação civil internacional.

\subsection{Concepção quadridimensional do território estatal}

Como ficou visto, o território estatal possui uma dimensão relativa ao comprimento da superfície, outra relativa à largura da mesma, uma terceira dimensão que representa a profundidade e altura (subsolo, solo e espaço aéreo), podendo, assim, ser representado por aquela pirâmide irregular côncava, de base semi-esférica, 
com o vértice invertido situado no centro do planeta (subsolo e solo), projetando-se os lados da pirâmide em direção ao ponto onde termina a atmosfera (espaço aéreo).

As bordas externas dessa figura geométrica são as fronteiras.

Mas há um conceito velho e um conceito novo de fronteira. A partir da distinção feita por Fawcet entre fronteira (zona) e limite (linha geodésica ou naturalgeográfica), bem como a partir do conceito de "isóbora política" formulado por Ancel, reformularam-se os estudos sobre o tema, passando-se, como reflexo teórico necessário, a reformular o próprio conceito de espaço geográfico e de território estatal.

O território estatal (e suas fronteiras) deve ser estudado também em sua dimensão temporal, histórica, e não-somente espacial. Tomando de Braudel o conceito de "tempo social" as fronteiras devem ser interpretadas como disjuntores de "tempos desiguais" (Wanderley Messias da Costa). O espaço geográfico (assim como geográfico-político) é definido por Milton Santos como "acumulação desigual de tempos: Se o impacto de um sistema de tempo sobre uma fração de espaço não fosse recorrente, cada sistema temporal poderia imprimir completamente sua marca sobre o pedaço de espaço atingido; no entanto, pelo fato de que um sistema histórico anterior deixa resíduos, há uma superposição de traços de sistemas diferentes, exceto no caso de espaços virgens, tocados pela primeira vez por um impacto modernizador cuja origem se encontra em forças externas"

Tal concepção quadridimensional do território estatal é inafastável quando se tem por escopo a análise do processo de formação do território brasileiro. $\mathrm{Na}$ verdade, como se pretende demonstrar, tal processo inicia-se numa fase préhistórica em relação ao surgimento do Direito Internacional, com a atuação da Santa Sé, como sujeito de Direito das Gentes, na divisão do mundo novo, então ignoto, entre as potências marítimas ibéricas. Tal processo, num segundo tempo, envolve acordos diplomáticos entre as duas potências navegadoras e a fixação de um primeiro desenho do território da Colônia portuguesa. Num terceiro tempo, altera-se a fronteira ocidental original por expansão humana e razões econômicas locais, seguida de ação diplomática da qual participa intensamente, em Madri, um filho do Brasil. Finalmente, num quarto estágio de tempo histórico-social, questões limítrofes pontuais são resolvidas por via diplomática ou arbitragem, configurando-se, ao cabo do processo, o atual desenho do território estatal brasileiro. 
2. Pré-História do Direito Internacional

\subsection{Os descobrimentos}

Antes do surgimento dos primeiros escritos técnico-jurídicos sobre as relações internacionais e sobre a necessidade de um ordenamento jurídico para reger a sociedade internacional (Alberico Gentili, 1551-1608; Hugo Grócio, 1583-1645), tal questão foi posta em termos teológicos, na Espanha.

De fato, em suas aulas de teologia escolástica, em Salamanca, o dominicano Francisco de Vitória (1486-1546), pioneiramente, começou por questionar a Justiça da guerra movida pelos conquistadores contra os conquistados, no Novo Mundo; concluía por afirmar a necessidade de um novo ramo jurídico, superior ao ordenamento dos povos interessados (espanhóis e ameríndios), para dirimir a questão. E o jesuíta Francisco Suarez (1548-1617), em torno do mesmo tema, ponderava que "se bem que cada cidade independente, cada república e cada reino constitua em si uma comunidade perfeita e formada por seus membros, contudo cada uma dessas comunidades é também, de certa forma, membro desse conjunto que é o gênero humano; nunca, de fato, essas comunidades podem se satisfazer a si mesmas, separadamente, a ponto de não terem necessidade de sua ajuda reciproca, de sua associação, de sua união, seja para o seu melhor bem-estar e sua melhor utilidade às relações econômicas, seja por causa de necessidades morais; por esse motivo, elas têm necessidade de algum direito que as dirija e as ordene nesse gênero de relações e de sociedade" ("De Legibus ac Deo Legislatore" livro II, cap. $19, \S 9^{\circ}$ trad. de Vicente Marotta Rangel).

O nascimento do Direito Internacional, assim, está intimamente ligado aos descobrimentos marítimos e, por isso, ao nascimento do Estado moderno, ao surgimento do mercantilismo, graças à introdução dos metais preciosos americanos no continente europeu.

\subsection{A Santa Sé como sujeito de Direito Internacional}

O papa, chefe da Santa Sé, sempre exerceu, cumulativamente, duas funções públicas: a de soberano da cristandade católica romana e a de soberano temporal de um Estado pontifício, que se assemelhava a outro qualquer da natureza laica. Ademais, dentre os soberanos, o papa colocava-se em situação de 
proeminência, elevando-se até o nível que, paralelamente, o colocava ao lado do imperador temporal do Sacro Império Romano Germânico; em razão disso, era ele quem ungia o imperador, era ele quem ditava regras sobre guerra, paz e tréguas de Deus, era ele quem arbitrava os litígios entre reis, príncipes e senhores. A Santa Sé, pois, era pessoa de Direito Internacional.

Com a unificação italiana, em 1870, as tropas do rei Vitor Emanuel II incorporaram ao reino os territórios pontifícios, dando-se-lhe a posse das edificações do Vaticano e resguardando-se-lhe os privilégios e imunidades de Direito Internacional, podendo a Santa Sé continuar a exercer os tradicionais direitos de legação (ativa e passiva) e de celebração de concordatas. Inegavelmente, a Santa Sé não poderia ser considerada um Estado, não-só por falecer-lhe território, mas, sobretudo, por inexistir o vínculo político-jurídico de nacionalidade de seus membros (inexistência de súditos). Tal situação cristalizou-se, em 1929, quando o primeiro-ministro Mussolini celebrou concordata com Pio XI, no reinado de Vitor Emanuel III.

Portanto, não sendo um Estado nem uma organização internacional (entendida esta, no sentido técnico, como associação de Estados), a Santa Sé, por razões meramente históricas, é sujeito de Direito Internacional.

E foi nessa condição, que, na fase que ousamos chamar de préhistórica do Direito Internacional, ela, a Santa Sé, editou regras de eficácia internacional, visando à repartição do mundo a ser descoberto entre as potências marítimas dos séculos XV e XVI.

\section{Os Reinos Ibéricos em disputa do Novo Mundo}

\section{1 - As bulas papais}

Numa época de insurreições na península itálica, no século XV. com incursões de franceses, os reis católicos de Espanha, Fernando (aragonês) e Isabel, deram apoio militar ao papa conterrâneo Alexandre VI (que era um Bórgia aragonês), além de terem-no reeleito. Em contrapartida, o papa Alexandre VI decidiu apoiar as pretensões estratégicas espanholas, em relação ao Novo Mundo a ser conquistado. Afinal, a Espanha havia reconquistado o território aos mouros estando ávida pelos descobrimentos. O papa Alexandre VI, antigo cardeal aragoné 
Rodrigo Bórgia, sentia-se ligado aos interesses espanhóis pelos laços de gratidão, senão de nacionalidade.

Assim, em 1493, quando do retorno de Colombo de sua viagem descobridora da América, o papa editou as bulas Eximiae Devotionis" e "Inter Coetera" que, no fundo, atribuíam à Espanha a posse de todas as terras descobertas além do oceano até então ignoto; editou uma terceira bula, no mesmo ano, também denominada Inter Coetera" partilhando entre Portugal e Espanha as terras que se situassem aquém e além de um meridiano que passava a cem léguas a oeste dos Açores e Cabo Verde, respectivamente. Tal partição ensejou inúmeras polêmicas e disputas, uma vez que os Açores e Cabo Verde se encontram a léguas de distância entre si, além de a medida "légua" não-obter consenso. Por essas duas bulas e mais duas outras emitidas também em 1493 ("Eximiae Devotionis II" e "Dudum Siquidem"), o papa espanhol acabava por atribuir à Espanha, no exercício daquela função regradora de Direito Internacional a que nos referimos acima (n. 2.2), a posse de todas as terras a serem encontradas em direção ao oeste, além do oceano.

\subsection{O Tratado de Tordesilhas}

A diplomacia portuguesa acabou por ensejar uma revisão dessas bulas por parte da Espanha. E a negociação culminou com o Tratado chamado "Capitulação da Partição do Mar Oceano" assinado na cidade de Tordesilhas, em 7 de junho de 1494. Tal Tratado foi ratificado pela Santa Sé, em 1506, por meio da bula Ea quae probono pacis"

Segundo as principais cláusulas desse Tratado, a Portugal seriam atribuídas as terras encontradas no oceano ou para além-dele, até meridiano que passasse a 370 léguas a oeste do arquipélago de Cabo Verde.

Essa delimitação (embora pouco precisa) leva historiadores, como Joaquim Norberto de Souza Silva, no século XIX, a formular a chamada "teoria da intencionalidade" da descoberta cabralina, reforçada pelo argumento de que Cristóvão Colombo, ao voltar de sua primeira viagem ao Novo Mundo, estivera em Portugal e ali se reunira demoradamente com o rei português D. João II, dando-lhe preciosas informações, antes de dirigir-se à Espanha.

A descoberta do Brasil foi considerada, à época, fato de importância secundária para Portugal; o Brasil atrairia a atenção da Corte só muito mais tarde, com o ciclo da cana no Nordeste e o declínio do Império português na Índia. 
4. A dilatação das fronteiras do Brasil

\subsection{O bandeirismo}

Em 1578, morre na batalha de Alcácer-Quibir o rei português D. Sebastião, sem deixar descendentes. Assume o trono seu tio, o cardeal D. Henrique, o qual, todavia, morre em 1580. Extingue-se a dinastia de Aviz, abrindo-se, assim, a crise monárquica portuguesa. Para resolvê-la, monta-se uma união pessoal: assume o trono português o rei de Espanha, Felipe II (neto de D. Manuel I), da casa de Habsburgo, o qual era também o titular do Império Sacro Romano Germânico. A União Ibérica irá durar até 1640 .

Uma primeira consequeência dessa união pessoal constituída na Ibéria vai ocorrer no Brasil: as invasões holandesas e as francesas, em decorrência de esses países estarem em guerra contra Felipe II. As resistências opostas aos invasores por lusitanos e brasileiros vai acabar moldando certo caráter patriótico e a consciência da nacionalidade.

Uma segunda conseqüência é apontada por alguns historiadores; inexistindo conflito de interesses na Ibéria (graças à unicidade da Coroa), o trânsito de pessoas ficou mais facilitado na América, o que propiciou ao bandeirismo a expansão de suas incursões para além do meridiano de Tordesilhas. Mas essa é uma questão polêmica. Jaime Cortesão, por exemplo, entende que, durante o período filipino, as colônias na América continuaram tão-separadas como já se encontravam antes da unificação, pois "bem longe de formar com a Espanha uma só nação, Portugal conservava todos os seus foros, liberdades e privilégios, usos e costumes, formando reino e coroa à parte, tanto na metrópole como nas províncias ultramarinas" (p. 78).

Depois de discutir acuradamente os pólos da polêmica a respeito, Synesio Sampaio Goes faz ponderações indiscutivelmente procedentes: "o que não se pode garantir é que o bandeirismo teria existido e se desenvolvido da mesma maneira se não tivesse havido a União Ibérica. Afinal, o movimento se iniciou nesse período e bem se pode imaginar que, sem a união, os espanhóis teriam tomado mais providências para defender as fronteiras orientais do Vice-Reinado do Peru" E prossegue: "com Portugal independente, ademais, os holandeses provavelmente não haveriam ocupado Pernambuco e feitorias portuguesas na África, fato que, 
provocando a escassez de escravos negros, estimulou o bandeirismo de apresamento de indigenas'. (pp. 57-58).

\subsection{O Tratado de Madri e Tratados posteriores}

Na metade do século XVIII, tanto Portugal quanto a Espanha começaram a sentir a necessidade de revisão do Tratado de Tordesilhas. Isso ocorreu porque, no Oriente asiático, tal meridiano foi desrespeitado pela Espanha, que se apossou das Filipinas; e, na América, luso-brasileiros já tinham ocupação efetiva do Amazonas até o Javari, do Mato Grosso até o Guaporé, e do Sul.

Nas negociações do Tratado-revisor, Portugal fazia-se oficialmente representar por Tomás da Silva Teles, visconde de Vila Nova Cesveira, que era embaixador português em Madri. Mas o verdadeiro diplomata negociador que conduziu ao aperfeiçoamento do Tratado de Madri era o santista Alexandre de Gusmão, então secretário d'El Rei D. João V O diplomata, nascido no Brasil, era profundo conhecedor de geografia e cartografia das terras da América, além de portador de imensa erudição.

Alexandre de Gusmão invocou princípio geral do Direito Romano clássico: "uti possidetis ita possideatis" para apoiar a pretensão brasileira afinal consagrada no Tratado de Madri, de 1750 . E a segunda linha de argumentação desenvolvida por Alexandre de Gusmão foi a de que seriam preferíveis linhas naturais (acidentes geográficos) a linhas geodésicas (como o meridiano), argumentação essa também acatada em Madri.

Em 1761, todavia, firmaram Portugal e Espanha, já com novos chefes de Estado, o Tratado de El Pardo, cujo texto afirmava ficarem cancelados e anulados todos os termos do Tratado de Madri. O diplomata Synesio Sampaio Goes entende que isso ocorreu porque a nova política, quer de Espanha de Carlos III, ferrenho opositor do acordo, quer de Portugal do marquês de Pombal, que se não-conformava com a cessão da Colônia de Sacramento feita por Gusmão, fez convergirem os interesses de ambos na revogação. Na verdade, o que se estabeleceu em El Pardo foi uma suspensão ou hiato nas negociações.

Em 1777, novo Tratado é assinado: o de Santo Ildefonso. De suas cláusulas constava que ao território da Colônia portuguesa se incorporariam as porções ocupadas ao norte e ao oeste da linha de Tordesilhas (dois terços de área ovredente an meridiano) e. em compensação, os Sete Povos das Missões integrariam 
a área atribuída à Espanha. Isso se deveu à forte exigência dos jesuítas e a sentimentos humanitários, uma vez que a aplicação do Tratado de Madri iria exigir a migração forçada de grupos indígenas que povoavam aquela região.

No primeiro ano do século XIX, Espanha e Portugal guerreiam e o reino luso perde Olivença, na Ibéria; em compensação, na América, luso-brasileiros reconquistam o território dos Sete Povos. Ainda em 1801 celebra-se o Tratado de Paz de Badajós, pondo fim ao conflito ibérico. Olivença permanece espanhola.

Quanto à Colônia de Sacramento, que havia sido fundada, por razões obviamente estratégicas, em 1680, por portugueses na margem oriental da entrada do Rio da Prata, foi tomada pelos espanhóis em 1726, os quais, em 1776 (após, portanto, a celebração do Tratado de Madri, de 1750), integram todo o atual Uruguai no Vice-Reinado do Prata. Porém, em 1821, o Uruguai é anexado ao Brasil, com o nome de Província Cisplatina, depois de ter sido ocupado militarmente por lusobrasileiros desde 1817 Recorde-se que, a esse tempo, a região pertencia à Argentina, que já era independente de Espanha desde 1816. Entre 1825 e 1828 trava-se a Guerra Cisplatina, entre Argentina e Brasil, em disputa do atual Uruguai; por meio da mediação britânica, Brasil e Argentina reconhecem, em 27 de agosto de 1828, a independência do Uruguai.

\section{Questões de fronteiras, após a Independência}

\subsection{Demarcação de limites, no Império}

O processo de formação jurídica do território estatal brasileiro deveuse à ação competente de nossa diplomacia, que cuidou de deixar incontestes nossos limites com os países vizinhos, sobretudo na Amazônia.

O primeiro Tratado celebrado pelo Brasil imperial com um vizinho amazônico teve como parte o Peru, em 1851. Era uma "Convenção Especial de Comércio, Navegação Fluvial, Extradição e Limites" A característica da negociação ínsita no Tratado estava em que o Brasil cedia ao vizinho direito de navegação pelas águas amazônicas e o Peru, em contrapartida, aceitava limites propostos pelo Itamaraty, que, a partir do princípio do "uti possidetis" partiam de linhas geodésicas perpendiculares a rios, incluindo Tabatinga, que fora um forte português originariamente construído em terras pertencentes à Espanha. 
Em 1859, foi celebrado Tratado com a Venezuela, denominado "Tratado de Limites e Navegação Fluvial" adotando-se o mesmo princípio. Trabalhos de campo (de demarcação) prosseguiriam por mais de um século: o ponto mais alto do Brasil, o Pico da Neblina, só foi descoberto em 1964.

Em 1867 firmou-se Tratado com a Bolívia, denominado "De Amizade, Limites, Navegação, Comércio e Extradição" tendo o Itamaraty usado da mesma estratégia, buscando confirmar o princípio do "uti possidetis"

Synesio Sampaio Goes assim sumaria a ação diplomática na demarcação amazônica no período imperial: 'um dos 'milagres' da História do Brasil é a Amazônia brasileira durante a maior parte de sua vida colonial o Estado do Grão-Pará e Maranhão, independente de Salvador e, depois, do Rio de Janeiro ter composto, com o 'Estado do Brasil', o relativamente homogêneo Império que nasceu com o grito do Ipiranga. Se é verdade que a unificação já havia sido feita em 1774, pelo Marquês de Pombal, é também verdade que as comunicações entre Belém e o Rio, à época da Independência, continuavam tãodifíceis quanto em 1621, quando se criou, exatamente por essa razão, o Estado do Maranhão' (p. 138).

\subsection{Demarcação de limites, na República}

a. A questão de Palmas

O território contestado (por Argentina e Brasil) de Palmas sempre esteve administrado pelo Brasil, como argumentou Rio Branco, advogado das pretensões brasileiras perante o árbitro escolhido por consenso, o presidente dos Estados Unidos da América, M. Grover Cleveland. O laudo, de 5 de fevereiro de 1895, deu como bem fundadas as razões do Brasil. Adverte Synesio Sampaio Goes que esta questão foi, do ponto de vista estratégico e militar, a mais importante matéria de fronteira conduzida por Rio Branco: "se a Argentina, o tradicional adversário, então superior em vários campos, ganhasse a contenda, o Rio Grande do Sul ficaria unido ao resto do Brasil por um estreito corredor de apenas $250 \mathrm{~km}$ (p. 147). 


\section{b. A questão do Amapá}

A controvérsia entre franceses e luso-brasileiros em torno do Cabo Norte datam da fundação de Belém (1616) por portugueses e de Caiena (1634) pelos franceses. Nesse interim, os portugueses expulsaram estrangeiros que ocupavam pontos às margens da foz estratégica do Amazonas. Em 1637, criaram a Capitania do Cabo Norte, para garantir as posições conquistadas. Mas sempre houve ocupações esporádicas de franceses e reações portuguesas. Vários tratados tentaram equacionar os limites com a Guiana (entre eles o de Utrecht, de 1713), mas os próprios textos dos tratados suscitavam dúvidas e incertezas, de parte a parte, quanto à exata situação dos rios tomados como limite. Por fim, em 1897. no Rio de Janeiro, firmouse compromisso arbitral, tendo sido designado árbitro o Conselho Federal suíço.

Mais uma vez o advogado das pretensões brasileiras foi o Barão do Rio Branco. O Colegiado Governamental suiço deu ganho de causa ao Brasil, em laudo proferido em $1^{\circ}$ de dezembro de 1900 .

\section{c. A questão com a Guiana Inglesa}

Inglaterra e Brasil negociavam, desde a segunda metade do século passado, a delimitação exata da fronteira com a Guiana Inglesa. A questão foi levada à arbitragem do rei italiano Vitório Emanuele III, que, em 1904, pronunciou seu laudo, em que traçou uma linha divisória, a qual, todavia, descontentou os brasileiros, pois atribuiu à Guiana Inglesa área maior do que a atribuída ao Brasil. "O que procurou o árbitro" ensina Synesio Sampaio Goes (p. 157), " alegando que os documentos exibidos pelas partes não constituem títulos históricos e jurídicos suficientes, foi dividir a região entre os contendores e adotar fronteiras naturais, rios e montes. Preferiu, entretanto, aos divisores de água das bacias, o que certamente seria mais justificável, os próprios cursos d'água. Para defender essa preferência foram alegadas razóes secundárias, de menores despesas e maiores facilidades de demarcação, já que os divisores correriam por uma região de campos periodicamente alagados"

O defensor do interesse brasileiro nessa questão foi Joaquim Nabuco. 


\section{d. A questão do Acre}

No final do século XIX, a Amazônia recebeu fluxos migratórios provindos do Nordeste brasileiro, em busca da atividade seringueira. A região limitada pela linha geodésica entre Brasil e Bolívia, onde se instalaram e exerciam seus trabalhos, não lhes era conhecida com exatidão.

Um dos seringueiros, Plácido de Castro, liderou uma revolta, ao saber que as terras que ocupavam eram bolivianas e que a Bolívia estava negociando a cessão da exploração econômica da região a uma empresa britânica, "Bolivian Syndicate" Toda a riqueza da região era, afinal, produzida por cerca de 60 mil brasileiros que a habitavam de longa data. O presidente boliviano, pessoalmente, começou a deslocar tropas para a área. O Barão do Rio Branco, então chanceler brasileiro, também fez com que tropas brasileiras para ali marchassem, dando como sua e oficial a interpretação de que a área pertencia ao Brasil.

Fez-se trégua e, depois de meses de negociação transcorrida em Petrópolis, foi assinado em 17 de novembro de 1903 o Tratado entre Bolívia e Brasil. A Bolívia cedia ao Brasil a imensa área correspondente ao atual Estado do Acre, mediante compensações: algumas territoriais (no Mato Grosso), algumas de prestação de serviço (construção da estrada de ferro entre Porto Velho e GuajaráMirim), outras indenizatórias (dois milhões de libras esterlinas).

e. Tratados com Equador, Colômbia e Peru

Em 1904, o Brasil celebra Tratado com o Equador (que tinha pretensão, contestada pelo Peru, na área limítrofe com o Brasil).

Em 1907. celebra-se Tratado de limites entre Brasil e Colômbia.

Em 1909, Brasil e Peru assinam Tratado de limites.

Completou-se, assim, a importante obra diplomática da consolidação das fronteiras desenhadas, a partir do descobrimento, pelos intrépidos lusobrasileiros que, no dizer de Guilherme de Almeida, "Brandiram achas e empurraram quilhas, vergando a vertical de Tordesilhas" 


\section{Conclusões}

Percebe-se que o processo de formação jurídico-política do território brasileiro começa embrionariamente ainda na pré-história do Direito Internacional, com papas editando bulas de partição dos oceanos e de terras além deles existentes. Tal processo perpassa por intrigas diplomáticas palacianas nos reinos ibéricos, com a curiosa e misteriosa estada de Colombo em Lisboa, na volta de sua primeira viagem ao Mundo Novo, continua com a celebração do Tratado de Tordesilhas e ganha novos aspectos emocionantes com o bandeirismo dos primeiros povoadores e seus descendentes brasileiros, à cata de índios e de ouro, no Sul e Oeste, e em busca de estabelecer núcleos de povoamento e extração, na Amazônia. Tal processo passa também pela obra diplomática do santista Alexandre de Gusmão, que, a serviço do Reino português, consolida e torna respeitado o princípio do "uti possidetis" em Madri. E percebe-se, finalmente, que o processo se cristaliza, quer por meios convencionais, quer por arbitragens internacionais, durante o Império e a República.

Quanto ao conceito de território estatal, a análise do processo de sua formação jurídico-política, sobretudo no caso do Brasil, vem demonstrar que esse elemento constitutivo do Estado não se reduz a mera figura geométrica tridimensional (com comprimento, largura e profundidade), mas que, ao contrário, ostenta uma quarta dimensão histórico-temporal, sem a qual não seria ele entendido na sua inteireza, como acumulação desigual de tempos.

São Paulo, abril de 1999.

7 Bibliografia

ACCIOLY Hildebrando. Limites do Brasil: a fronteira com o Paraguay' São Paulo, Cia. Edit. Nacional, 1938.

ARMITAGE, João. " História do Brasil' São Paulo, Itatiaia/Edusp, 1981.

BATH, Sérgio. "Cinco Tratados históricos (1494-1895)" Brasília, Instituto Rio Branco, 1980.

BevilacquA, Clóvis. "Direito Público Internacional" Rio, Francisco Alves, 1910, tomo 1, §§ 64 e ss.

BURNS, Edward McNall. "História da Civilização Ocidental" trad. de Lourival Gomes Machado, Porto Alegre, Globo, 1948. 
CERVo, Amado e BuEno, Clodoaldo. "História da Política Exterior do Brasil" São Paulo, Ática, 1992.

CORTESÃO, Jaime. Alexandre de Gusmão e o Tratado de Madri" Rio, Instituto Rio Branco, s.d., $8 \mathrm{v}$.

COSTA, Wanderley Messias da. "Geografia Política e Geopolítica" São Paulo, Hucitec/Edusp, 1992.

EU, Luis Filipe M. F Gastão de Orleans, Conde d'. Viagem militar ao Rio Grande do Sul' São Paulo, Itatiaia/Edusp, 1981.

FAUSTO, Boris. História do Brasil' São Paulo, Edusp, 1995.

GOES, Synesio Sampaio. Navegantes, Bandeirantes, Diplomatas" Brasília, Ipri, 1991.

GUICHONNET, Paul e RAFFESTIN, Claude. "Géographie des frontières' Paris, Presses Universitaires de France, 1974.

HEREDIA, Vicente Beltrán de. "Francisco de Vitoria" Barcelona, Labor, 1939.

HOLANDA, Sérgio Buarque de. "Visão do paraíso: os motivos edênicos no descobrimento e colonização do Brasir" São Paulo, Cia. Editora Nacional, 1977.

RANGEL, Vicente Marotta. Direito e Relações Internacionais" $5^{\mathrm{a}}$ ed., São Paulo, Revista dos Tribunais, 1997

REZEK, J. F "Direito Internacional Público" 5a ed., São Paulo, Saraiva, 1995.

ROBLEDO, Antonio Gómez. Fundadores del Derecho Internacional: Vitoria, Gentili, Suárez, Grocio" México, Unam, 1989.

SANTOS, Milton. "Por uma geografia nova" São Paulo, Hucitec/Edusp, 1978, pp. 203-211.

SERRA, Antonio Truyol y. Fundamentos de Derecho Internacional Publico" Madri, Tecnos, 1977, caps. IX e X, pp. 131-223. 